\title{
Untreated Childhood Supratentorial Primitive Neuroectodermal Tumor
}

National Cancer Institute

\section{Source}

National Cancer Institute. Untreated Childhood Supratentorial Primitive Neuroectodermal

Tumor. NCI Thesaurus. Code C115956.

A finding of supratentorial primitive neuroectodermal tumor in childhood that has not been treated. 